\title{
Supply Chain Benefits Distribution Model Based on Improved Shapley Value Method
}

\author{
Yuanyuan Zhang ${ }^{1, a}$ and Haihong Jiang ${ }^{1, b}$ \\ ${ }^{1}$ School of Management Science and Engineering, Shandong Institute of Business and \\ Technology,264005 Yantai, China \\ afrank_zyy@sohu.com, bjianghh0302@yahoo.com.cn
}

\begin{abstract}
Keywords: Collaborative Benefit Distribution; Shapley Value algorithm; Supply chain; Electronic Commerce Capability
\end{abstract}

\begin{abstract}
A variety of factors are integrated in the benefit distribution model of supply chain coordination. The factors that affect the benefit distribution include E-business ability, the risk level and the value of the investment. Three indicators are used to measure the enterprise's E-business ability. These are: the proportion of funds related to the construction and application of e-business, percentage of e-business personnel accounted for all staff, percentage of e-business transactions accounted for the total business turnover. The risk is measured by market risk, technical risk, cooperative risk and information risk .According to the above analysis, an improved Shapley value method is created for the coordination of supply chain enterprises. In a certain sense, the improved Shapley value method for multiple factors comprehensive correction improves the rationality and comprehensiveness of the benefit allocation scheme.
\end{abstract}

\section{Introduction}

As Simatupang said supply chain collaboration is two or more members join together to create greater interest than acting alone, such as lower inventory levels, shorten cycle, faster turnaround, More competitive and so on [1-2].Supply chain enterprise strengthen supply chain flexibility, maximize supply chain collaborative benefits by means of joint decision-making, information-sharing, working together.

In 1990s, the emergence of e-commerce and the application in the supply chain coordination process has greatly changed the supply chain management model. With the help of e-commerce technology, in the collaborative process sharing information became more convenient and accurate, funds flow and logistics flow circulate more smoothly. E-commerce technology improved the efficiency and performance of supply chain collaboration. Member enterprises of supply chain collaboration can coordinate and control as a whole. The different enterprises build the supply chain to to maximize benefits. Each enterprise is independent economic entity. Therefore, the pursuit of the maximum personal interest is still the biggest power.

Therefore, the rational allocation of interests can promote the healthy development of supply chain collaboration and effective solid supply chain partnership. Have to pay to have the harvest, the member enterprises in the supply chain will work harder and more actively involved in the construction and development of supply chain. How to rationally distribute these benefits is a worth studying subject.

\section{Shapley Value Method Prototypes}

Shapley Basic Theory. Shapley L.S introduced Shapley method in 1953. This method is used to solve benefit distribution in cooperative game [3]. In the alliance composed by multiple members, the cooperation of any number of members can create a certain profit. The interests of the members of the alliance are consistent, and there is no antagonism. Therefore, the income of all members enterprise cooperation is the largest. Shapley value method is one of methods used to solve the biggest benefits allocation. 
In Shapley value method, the benefits of participants are detemined by the constribution made in the process of cooperation. Members of the alliance can make contribution in different cooperation with other enterprises. The weighted mean value of marginal contribution of the participants in each cooperation is equal to the benifit quota of this member.

A cooperative alliance named $N(M=\{1,2 \cdots n\})$ is composed of $n$ members. A cooperative alliance of any number of $\mathrm{N}$ is named $\mathrm{s}$. Let real-valued function $\mathrm{V}(\mathrm{s})$ show revenue created by $\mathrm{s}$.

Let $\varphi_{i}(v)$ show the benefit quota which member i should get. The formula is expressed as:

$$
\begin{gathered}
\varphi_{i}(v)=\sum_{s \in S_{i}}\{w(|s|)[v(s)-v(s \backslash i)]\}, i=1,2, \cdots, n \\
w(|s|)=\frac{(n-|s|) !(|s|-1) !}{n !}
\end{gathered}
$$

$\mathrm{s}$, which contains the member $\mathrm{i}$, is a subset of the set $\mathrm{N}$. The number of members in $\mathrm{s}$ is $|\mathrm{s}|, \mathrm{w}(|\mathrm{s}|)$ is weighted factors. $\mathrm{V}(\mathrm{s} / \mathrm{i})$ is revenue created by cooperative alliance which not contains the member i.

Improved Collaborative Benefit Distribution Model of Electronic Commerce Supply Chain. In Shapley value algorithm, the contribution of each enterprise in cooperation determines the quantity of profit distribution. Income and contribution are positively correlated. This allocation method ensures the fairness and justice in a certain degree, but ignores to manage these factors which exist in the process of enterprises making the contribution. In the same supply chain collaboration alliance, the same contribution may generate in different environment. The risk, investment capital and electronic commerce capability of enterprise is not the same. Therefore, it is necessary to consider those important factors when profits are allocated. This can improve the rationality of the allocation scheme and ensure prospect of collaborative supply chain.

Referring to various factors, collaborative benefit distribution model is designed comprehensively. Using e-commerce capabilities, magnitude of risk, input resource value of member enterprises to adjust the Shapley value method prototype, build a more comprehensive and reasonable allocation scheme.

\section{Factors of Supply Chain Coordination Benefit Distribution}

E-commerce Capabilities of Enterprise. E-commerce systems are used to support enterprise business operations. By means of information technology, e-commerce make share enterprise internal knowledge smoothly, information flow in high speed and easy to collect external information. It effectively improves the business efficiency and the market reaction capacity of enterprise. Member enterprises in the supply chain build information trading platform to shorten the distance between the upstream and downstream partners. It is possible to get and exchange information and real-time capital flow. The emergence of e-commerce technology improved coordination ability and agility of supply chain. "Time is money". In the development of the chain, each member enterprise can determine the smooth degree of the whole chain. Cooperation and communication are very important in the supply chain. Therefore, electronic commerce capability of each member enterprises affects the whole performance and development.

E-commerce capability includes e-commerce system capability and e-commerce services capability [4] Those two kinds of ability are explained in Table 1. 
Table 1 Composition of electronic commerce capability

\begin{tabular}{|l|l|l|}
\hline $\begin{array}{l}\text { Item } \\
\text { No. }\end{array}$ & Name & Description \\
\hline 1 & E-commerce system capability & $\begin{array}{l}\text { the system construction capability and the construction } \\
\text { achievement. This capability emphasises on the } \\
\text { availability, security, reliability and robustness of the } \\
\text { electronic commerce system }\end{array}$ \\
\hline 2 & E-commerce service capability & $\begin{array}{l}\text { the business support degree of e-commerce system in } \\
\text { the enterprise business process. }\end{array}$ \\
\hline
\end{tabular}

The electronic commerce capability coefficient of each member is marked as $e_{i}$, so $e_{i}=\frac{e_{i 1} \times e_{i 2} \times e_{i 3}}{\sum_{\mathrm{i}=1}^{\mathrm{n}} e_{i 1} \times e_{i 2} \times e_{i 3}}$

Based on the electronic commerce capability factor, the benefit allocation of member $\mathrm{i}$ is $\varphi_{e i}(v)=e_{i} V(n), i=1,2,3, \cdots n$

Risk Factors. Four risk indicators are used to measure magnitude of risk including market risk, technical risk, cooperative risk and information risk[5]. The risk of each member is marked as $\mathrm{R}_{\mathrm{i}}$. So $R_{i}=1-\left(1-R_{i M}\right)\left(1-R_{i T}\right)\left(1-R_{i C}\right)\left(1-R_{i I N}\right)$. The risk coefficient of member $\mathrm{i}$ is $r_{i}=\frac{R_{i}}{\sum_{i=1}^{n} R_{i}}=\frac{1-\left(1-R_{i M}\right)\left(1-R_{i T}\right)\left(1-R_{i C}\right)\left(1-R_{i I N}\right)}{\sum_{i=1}^{n} 1-\left(1-R_{i M}\right)\left(1-R_{i T}\right)\left(1-R_{i c}\right)\left(1-R_{i I N}\right)}$

. Based on the risk factors, the benefit allocation of member $i$ is

$$
\varphi_{r i}=\frac{r_{i}}{\sum_{i=1}^{n} r_{i}} V(n), i=1,2, \cdots n
$$

\section{Resource Facters}

The resource investment of member enterprises should also be an important standard in supply chain benefit distribution. The benefit distribution can be measured by calculating the resource investment.

value of resource. Each member enterprise invests resources to maintain and promote the coordinated operation and development of the supply chain. This resources mainly include the necessary labor costs, the cost of raw materials and the machine cost, etc.[6] Member enterprises generally invest a variety of resources. The cost value which enterprise $i$ has invested resource $j$ is marked as $\mathrm{Pij}(\mathrm{Pij} \geqslant 0)(\mathrm{i}=1,2, \ldots, \mathrm{n} ; \mathrm{j}=1,2, \ldots, \mathrm{m})$. If member enterprise has not invest the resourse, the cost price is set to zero. The market cost value of investment resources of each member

$$
P=\left(\begin{array}{cccc}
P_{11} & P_{12} & \cdots & P_{1 m} \\
P_{21} & P_{22} & \cdots & P_{2 m} \\
\cdots & \cdots & \cdots & \cdots \\
P_{n 1} & P_{n 2} & \cdots & P_{n m}
\end{array}\right)_{n \times m} .
$$

Adjustment coefficient for resource value. Due to the different status, supply chain enterprises play a different role in the coordination. The high cost value of resources is not equal to the production of the corresponding benefits. This high cost may be caused by the waste of resources, inefficiency and other reasons. Therefore, the importance of the supply chain enterprise should be taken into account when measuring the resourse value [7].

The weight coefficient $K_{j}$ is designed to show the importance of the resources. The value of $K_{j}$ is positively correlated with the importance of resources. The adjustment coefficient of $\mathrm{m}$ resources 
value is: $\quad K=\left(\begin{array}{c}k_{1} \\ k_{2} \\ \cdots \\ k_{m}\end{array}\right)_{n \times 1}$. The adjustment coefficient which enterprise $\mathrm{i}$ has invested resource $\mathrm{j}$ is marked as $\mathrm{Vij}=\mathrm{Pij} \cdot \mathrm{Kj}$.

The resource investment value of each member enterprises in the supply chain is marked as $P K=\left(\begin{array}{cccc}P_{11} & P_{12} & \cdots & P_{1 m} \\ P_{21} & P_{22} & \cdots & P_{2 m} \\ \cdots & \cdots & \cdots & \cdots \\ P_{n 1} & P_{n 2} & \cdots & P_{n m}\end{array}\right)_{n \times m} \times\left(\begin{array}{c}k_{1} \\ k_{2} \\ \cdots \\ k_{m}\end{array}\right)_{m \times 1}=\left(\begin{array}{c}V_{1} \\ V_{2} \\ \cdots \\ V_{n}\end{array}\right)_{n \times 1}$,the total investment value of each supply chain collaboration

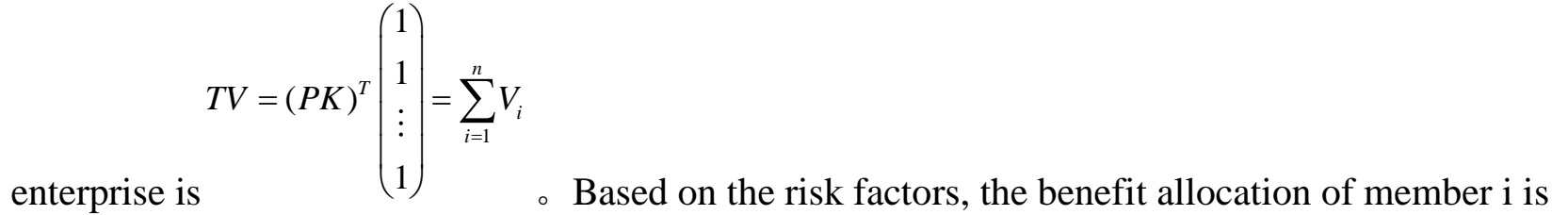

$$
\varphi_{k i}(v)=\frac{V_{i}}{T V} V(n), i=1,2,3, \cdots n
$$

The weight of factors. The weight of each factor is calculated using analytic hierarchy process. $\mathrm{fb}$ 、 fr、 fk and fe are used to mark the supply chain revenue contribution, enterprise e-commerce capabilities, the magnitude of risk and the weight of investment value.

Collaborative benefit distribution model of Supply chain. In the process of supply chain distribution, revenue contribution, enterprise e-commerce capabilities, the magnitude of risk and investment value are considered. The proportion of the four elements in different supply chain is also different.Therefore, considering the various factors that affect the distribution of the supply chain, the distribution of the supply chain collaboration which based on e-commerce can be expressed as:

$$
\varphi_{i}(v)^{*}=f_{b} \varphi_{i}(v)+f_{e} e_{i} V(n)+f_{r} \frac{r_{i}}{\sum_{i=1}^{n} r_{i}} V(n)+f_{k} \frac{V_{i}}{T V} V(n), i=1,2, \cdots n
$$

\section{Summary}

The efficiency, fluency and ability to create value of supply chain determined the competition ability of supply chain member enterprise. Therefore, enterprises in the supply chain collaboration regard creating the maximum synergistic benefits as an important task. An another important issue is their share of a cup of a thick soup.It has an important practical significance to fairly and rationally distrubute supply chain collaboration benefits and ensure prospect of collaborative supply chain. Based on Shapley value method prototype, a improved Shapley value method of supply chain collaborative enterprise profit allocation model is proposed. Enterprise e-business capabilities, risk, resource factors were integrated in this model.

\section{Acknowledgement}

This work was financially supported by the Shandong Province humanities and social Sciences project (J13WG62), Shandong Provincial Natural Science Foundation, China(ZR2014GQ015).

\section{References}

[1] Simatupang T M,Sridharan Management,2005,16(2):257-274 .

R. The International Journal of Logistics 
[2] Simatupang $T$ M,Sridharan R. A benchmarking scheme for supply chain collaboration[J].Benchmarking: An International Journal,2004,11(1):9-30.

[3] Lloyd Shapley.A value for N-Person Games[M].USA:Princeton University Press,1953:307-318.

[4] WU Jin-nan,ZHONG Wei-jun, Investigating the Impact of E-business Capability on Supply Chain Performance[J]. Chinese Journal of Management Science. 2011, 19(01): 38-42.

[5] Chenjian, Feng Weidong. Construction and management of Virtual Enterprise[M]. Beijing: Tsinghua University press. 2002:81-91.

[6] Zang Xiuqing, Zhang Xiaomin. Study on the interests distribution of the port supply chain. Statistics \& Decision. 2012 (16) : 45-47.

[7] Wang Peng. Research on Profit Allocation Model of Enterprise Cooperation in Supply Chain[D]. Huazhong University of Science and Technology. 2006:44.

[8] Sunil Chopra: Supply Chain Management (China Renmin University Press, China 2013),p.132-138

[9] Liu Baohong:Purchasing and Supply Chain Management(China Machine Press. China, 2015), p.56-65

[10] Ma Shihua, Lin Yong: Supply Chain Management(China Machine Press. China, 2014), p.88-90. 